\title{
Effect of Substituents on the O-O Bond Rupture of Different Organic Peroxides in Toluene Solution
}

\author{
G. N. Eyler, A. I. Cañizo, C. M. Mateo, E. E. Alvarez and R. K. Nesprías \\ Laboratorio de Química Facultad de Ingeniería U.N.C.P.B.A., Olavarría, Argentina \\ E-mail: knespria@fio.unicen.edu.ar
}

\begin{abstract}
The thermal decomposition reaction of cyclic organic peroxides was studied in toluene solution in a wide temperature range. The kinetic data show an important substituent effect on the unimolecular homolysis of the O-O bond of these molecules.
\end{abstract}

\section{Introduction}

Previous studies [1] demonstrated that a solvent effect is operative on the kinetic parameters of the thermal decomposition reaction of cyclic organic peroxides in solution.

In this work, effects of substituents on the O-O bond homolytic rupture of s cyclic organic peroxides with structures like 1,2,4,5-tetroxanes, 1,2,4-trioxanes, 1,2,4,5-trioxazines and 1,2,4,5,7,8-hexaoxacyclononanes were evaluated.

\section{Experimental}

Organic peroxides were prepared in this laboratory with methods described elsewhere [2]. The cyclic peroxides remaining in the solution were quantitatively determined by GC.

\section{Results and Discussion}

The thermal decomposition reaction of cyclic organic peroxides reported in this work follow a first order kinetic law up to c.a. $50 \%$ peroxide conversion. The rate constant values at different temperatures were determined. A linear relationship between the activation enthalpies and entropies of the unimolecular thermolysis reaction of the cyclic peroxides can be found (Fig. 1). The ranges of activation enthalpies and entropies $\left(\Delta \Delta \mathrm{H}^{\#}: 22.2 \mathrm{kcal} / \mathrm{mol}\right.$ and $\Delta \Delta \mathrm{S}^{\#}: 54.2$ e.u.) are large compared to the probable errors of those parameters. The highest activation parameter values were found for nine membered ring (1,2,4,5,7,8-hexaoxacyclononanes derived from acetone, diethylketone and cyclohexanone). 


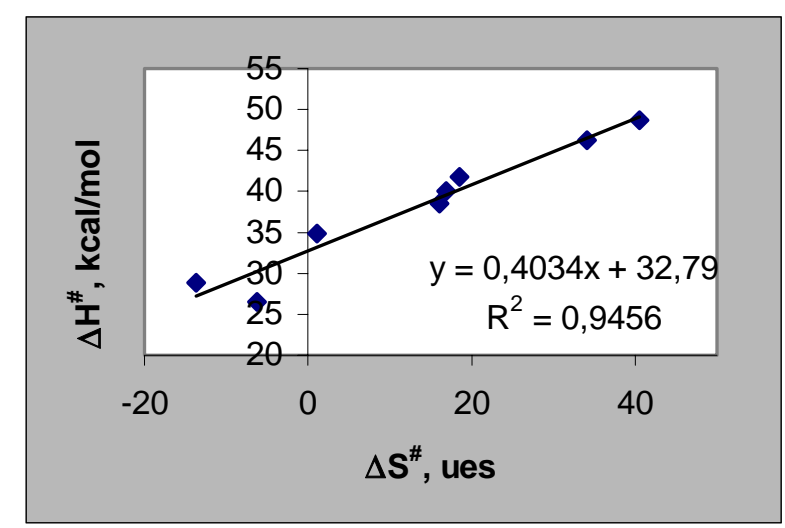

Figure 1. Compensation Law according to Leffler criteria [3] applied to cyclic organic peroxides in toluene.

The lowest values obtained corresponded to a six membered ring, the 1,2,4,5-tetraoxacyclohexanes derived from acetone. In both series considered (six or nine members rings) the cyclic peroxides with methyl groups as substituents showed the lowest activation parameters, probably because of the reduce steric hindrance and highly interaction with the solvent.

The slope of the representation in Fig. 1 corresponds to the "isokinetic temperature" $(\beta)$ which in this case is $130.4^{\circ} \mathrm{C}$.

Acknowledgements: This research project was financially supported by the Facultad de Ingeniería, the SECyT de la Uiversidad Nacional del Centro de la Provincia de Buenos Aires and CIC de la Provincia de Buenos Aires.

\section{References}

1. Cafferata, L. F. R.; Eyler, G. N.; Cañizo, A. I.; Alvarez, E. E. J. Org. Chem. 1991, 56, 411.

2. Mc Cullough, K. J.; Morgan, A. R.; Nonhebel, D. C.; Pauson, P. L.; White, G. J. J. Chem. Res. Synop. 1980, 34, M 0601.

3. Leffler, J. E. J. Org. Chem. 1955, 20, 1202. 